\title{
Electrocardiography Characteristics of Isolated Non-Compaction of Ventricular Myocardium in Japanese Adult Patients
}

\author{
Masaaki Shoji, MD; Takeshi Yamashita, MD; Tokuhisa Uejima, MD; Kazuo Asada, MD; \\ Hiroaki Semba, MD; Takayuki Otsuka, MD; Koichi Sagara, MD; Hitoshi Sawada, MD; \\ Mitsuaki Isobe, MD; Tadanori Aizawa, MD
}

\begin{abstract}
Background: Isolated non-compaction of ventricular myocardium (INVM) is characterized by persistent embryonic myocardial morphology without other cardiac anomalies. Congestive heart failure, critical arrhythmias, and systemic thromboemboli are known as major manifestations during childhood. Recently it was reported that there are some patients who seem apparently healthy in adult INVM. Clinical characteristics including that for electrocardiograms (ECG) of adult INVM, however, are unknown for Japanese subjects.
\end{abstract}

Methods and Results: From 24,082 patients who underwent echocardiography between June 2000 and June 2007, 187 patients $(0.78 \%, 41.3 \pm 16.8$ years, 122 male) were identified as having INVM according to the criteria proposed by Oechslin et al. Although fatal ventricular arrythmias and thromboembolic events occurred in 2 patients and in 1 patient, respectively, the rest had no severe cardiac complications. Normal ECG findings were found only in $24.6 \%$ of the patients. Most of the ECG abnormalities, however, were non-specific: ST-T changes in $35.2 \%$ and bundle branch block in $14.9 \%$. Notably, Brugada-like ECG was frequently seen in the present Japanese INVM patients (3.2\%). The incidence of these ECG findings was not dependent upon the extent of non-compaction.

Conclusions: The prevalence and ECG findings of adult Japanese INVM patients in a hospital-based clinical practice have been identified. (Circ J 2010; 74: 1431-1435)

Key Words: Echocardiography; Electrocardiogram; Isolated non-compaction of ventricular myocardium

$\mathbf{N}$ on-compaction of the ventricular myocardium, presumably caused by compaction arrest in the endocardial layer and also in the mid-layer of myocardium, is well-known as one of the causes for cardiomyopathy. Isolated non-compaction of ventricular myocardium (INVM), first described in 1990, is characterized by persistent embryonic myocardial morphology without any other cardiac anomalies. $^{1}$

Until now there have been many case reports on INVM manifesting with congestive heart failure, critical arrhythmias, and systemic thromboemboli. ${ }^{1-6}$ They are mostly diagnosed during childhood. ${ }^{7-9}$ In contrast, adult INVM patients are often found incidentally without such severe conditions. ${ }^{6,10,11}$ The clinical characteristics of these apparently healthy cases remain unclear. The aim of the present study was therefore to clarify their clinical characteristics with special reference to their electrocardiograms (ECG).

\begin{abstract}
Methods
Study Population

From 24,082 Japanese adult patients ( $\geq 15$ years old) who underwent echocardiography (UCG) between June 2000 and June 2007 at Cardiovascular Institute, we retrospectively selected INVM Japanese patients without any other cardiac diseases, and identified 187 Japanese patients $(0.78 \%, 41.3 \pm$ 16.8 years, 122 male). With regard to UCG definitions of INVM for screening, we used the proposal by Oechslin et al. ${ }^{2}$ They are (1) absence of coexisting cardiac abnormalities; (2) a 2-layer structure with a maximal end systolic ratio on non-compacted to compacted layers $>2$; and (3) existence of color Doppler evidence of deep perfused intertrabecular recesses.

In all cases, medical history and standard 12-lead ECG (paper speed: $25 \mathrm{~mm} / \mathrm{s}$, calibration: $1 \mathrm{mV}=10 \mathrm{~mm}$ ) were surveyed. ECG diagnoses were made by attending physicians not
\end{abstract}

Received February 7, 2010; revised manuscript received March 12, 2010; accepted March 14, 2010; released online May $27,2010 \quad$ Time for primary review: 9 days

Department of Cardiology (M.S., T.Y., T.U., K.A., H. Semba, T.O., K.S., H. Sawada, T.A.), Cardiovascular Institute, Tokyo; Department of Cardiovascular Medicine (M.S., M.I.), Tokyo Medical and Dental University, Tokyo, Japan

Mailing address: Masaaki Shoji, MD, Department of Cardiology, Cardiovascular Institute, 7-3-10 Roppongi, Minato-ku, Tokyo 106-0032, Japan. E-mail: shozy_corner@hotmail.com

ISSN-1346-9843 doi:10.1253/circj.CJ-10-0101

All rights are reserved to the Japanese Circulation Society. For permissions, please e-mail: cj@j-circ.or.jp 


\begin{tabular}{|lc|}
\hline Table 1. Reasons for Hospital Visit & No. patients (\%) \\
Consultation & $105(56.1)$ \\
Electrocardiogram abnormalities & $58(31.0)$ \\
Arrhythmia & $13(7.0)$ \\
Cardiac murmur & $10(5.3)$ \\
Hypertension & $7(3.7)$ \\
Palpitation & $4(2.1)$ \\
Chest pain & $4(2.1)$ \\
Others & $9(4.8)$ \\
Symptoms & $72(38.5)$ \\
Palpitation & $27(14.4)$ \\
Chest pain & $21(11.2)$ \\
Chest oppression & $18(9.6)$ \\
Others & $6(3.2)$ \\
Health check-up & $10(5.3)$ \\
\hline
\end{tabular}

in a blinded fashion. Because there were variations in the extent of non-compaction, we divided them into the following two types of INVMs: those with extensions from the apex up to the level of papillary muscles (broad extension) and those with lesions located only in the apex (non-broad extension).

The ECG criteria in the present study were as follows: (1) Brugada-like ECG; right bundle branch block (RBBB) or r' with persistent ST segment elevation $(\geq 0.2 \mathrm{mV})$ in lead $V_{1}$ and/or $\mathrm{V}_{2}$ followed by a negative $\mathrm{T}$ wave or a saddle-back ST-T morphology; (2) deep Q waves: Q wave duration >0.04 s and depth $>25 \%$ of the $\mathrm{R}$ wave voltage; (3) poor $\mathrm{R}$ wave progression: $\mathrm{R}$ wave voltage in lead $\mathrm{V}_{3}<0.3 \mathrm{mV}$ without $\mathrm{R}$ wave regression in $\mathrm{V}_{1-3}$; (4) high voltage: $\mathrm{S}$ in lead $\mathrm{V}_{1}$ or $\mathrm{V}_{2}$ (whichever is largest) $+\mathrm{R}$ in lead $\mathrm{V}_{5}$ or $\mathrm{V}_{6}$ (whichever is largest) $\geq 3.5 \mathrm{mV}$; (5) ST elevation: ST segment elevation $>0.05 \mathrm{mV}$ in the limb leads and $\mathrm{aVR}$ lead or ST segment elevation $>0.1 \mathrm{mV}$ in the pre-cordial leads; (6) ST depression: ST junction depression $\geq 0.1 \mathrm{mV}$ and ST segment horizontal or downward sloping in any of leads I, II, $\mathrm{aV}_{\mathrm{L}}, \mathrm{aV}$, or in the pre-cordial leads; (7) T wave abnormalities: T wave inversion except in $\mathrm{a} V_{R}$ and $V_{1}$, flat $T$ ( $T$ wave voltage $<1 / 10$ voltage compared with $\mathrm{R}$ wave in the lead); (8) intra-ventricular conduction disorder: some abnormalities of QRS morphology except RBBB, LBBB and axis deviation; (9) SSS: sinus bradycardia $(<50$ beats/min), sinus arrest or exit block; (10) axis deviation: frontal plane mean QRS axis $<-30^{\circ}$ (left axis deviation) or frontal plane mean QRS axis $>90^{\circ}$ (right axis deviation).

\section{Statistical Analysis}

Data are expressed as mean \pm SD. Differences in proportion between the groups were analyzed on chi-square test. Differences with $\mathrm{P}<0.05$ were considered statistically significant.

\section{Results}

\section{Clinical Characteristics}

Among 24,082 patients who underwent UCG, 187 patients were diagnosed as having INVM $(0.78 \%)$. Their mean age was $41.3 \pm 16.8$ years, and $65.2 \%$ were male. They visited Tokyo Medical and Dental Hospital for various reasons (Table 1): 90 patients (48.1\%) for consultation for ECG abnormalities and arrhythmias and so on from other hospitals, 72 patients $(38.5 \%)$ with some complaints (palpitation and chest pain), and 11 patients $(5.9 \%)$ for health check-up. It should be noted that $31.0 \%$ of the patients visited for evaluation of some ECG abnormalities. Heart failure was observed in 8 patients $(4.3 \%)$. Funnel chest was observed in 14 patients $(7.5 \%)$. Their comorbidities included hypertension $(n=26,13.9 \%)$, dyslipemia $(n=15,8.0 \%)$, ischemic heart disease $(n=5,2.7 \%)$, and diabetes mellitus $(n=1,0.5 \%)$. A history of thromboembolic event was observed only in 1 patient $(0.5 \%)$.

A variety of cardiac arrhythmias were observed in their ECG or history: atrial fibrillation $(n=9)$, supraventricular tachycardia $(n=5)$, ventricular extrasystole $(n=15)$, sick sinus syndrome and atrioventricular block $(n=4)$, atrial flutter $(n=1)$, and ventricular tachycardia/fibrillation $(n=2$ with implanted ICD).

\section{UCG Findings}

UCG demonstrated broad extension of non-compaction in 15 patients $(8.0 \%)$ and local non-compaction limited in apex (non-broad extension) in the remaining 172 patients (92.0\%). There were no significant differences in age and sex between the groups (Table 2). Their average left ventricular ejection fraction (LVEF) was preserved (approximately 60\%) and was not significantly different between the groups.

\section{ECG Findings}

On ECG a variety of abnormal findings were frequently observed (Table 3 ). Surprisingly, only 46 patients $(24.6 \%)$ had normal ECG, although this figure should be estimated upon a hospital-based analysis. The proportion of patients with normal ECG was not significantly different between the nonbroad extension $(25.0 \%)$ and the broad extension group $(20.0 \%)$.

ST elevation (17.6\%) and T wave abnormalities (13.9\%) were the most common ECG abnormalities. In addition, SSS and/or atrial fibrillation were frequently observed in $12.3 \%$ of the patients, although these ECG abnormalities should be non-specific. Notably, Brugada-like ECGs were also frequently observed in $3.2 \%$ of the patients (Figure), which is remarkably higher than that in the general population. One patient with Brugada-like ECG experienced VF and underwent ICD implantation. There were no significant differences in the incidence of these ECG abnormalities between the non-broad extension and the broad extension group.

\section{Discussion}

The major findings of the present study were as follows: (1) a hospital-based analysis showed that INVM was present in $0.78 \%$ of Japanese patients undergoing UCG; (2) only $24.6 \%$ of these patients had normal ECG findings; and (3) most of the ECG findings were non-specific with an exception of Brugada-like ECG.

In contrast to previous studies that focused upon the morphologic features of the ventricle and the prognosis in INVM,${ }^{2-4}$ the present study was designed to describe the characteristics of Japanese adult INVM. In contrast to child patients, the adult patients were frequently diagnosed incidentally. ${ }^{6,10,11}$

A recent study reported the characteristics of adult INVM $(\mathrm{n}=78)$ on a hospital-based analysis. ${ }^{5}$ The mean patient age at diagnosis was $42 \pm 16$ years and $71 \%$ were men. The present study with Japanese patients identified a similar patient profile. The prevalence of INVM has been reported at between $0.014 \%$ and $0.16 \% .^{2,4,12}$ The present study showed a much higher prevalence because of its hospital-based nature, but we should recognize that adult INVM is not a rare disease. 


\begin{tabular}{|lccc|}
\hline \multicolumn{2}{|c|}{ Table 2. Echocardiography Characteristics } & & \\
& All patients & Non-broad extension & Broad extension \\
Patients, $\mathrm{n}$ & 187 & 172 & 15 \\
Male, $\mathrm{n}(\%)$ & $123(65.8)$ & $113(65.7)$ & $10(66.7)$ \\
Mean age at diagnosis, years & 41.3 & 41.4 & 40.7 \\
Left ventricular ejection fraction, $\%$ & 62.2 & 62.7 & 56.3 \\
\hline
\end{tabular}

\begin{tabular}{|lccc|}
\hline Table 3. Electrocardiography Characteristics & No. patients (\%) & $\begin{array}{c}\text { No. patients with } \\
\text { non-broad extension } \\
\text { of non-compaction (\%) }\end{array}$ & $\begin{array}{c}\text { No. patients with } \\
\text { broad extension } \\
\text { of non-compaction (\%) }\end{array}$ \\
Normal & $46(24.6)$ & $43(25.0)$ & $3(20.0)$ \\
SSS and/or AF & $13(7.0)$ & $12(7.0)$ & $1(6.7)$ \\
AV block & $6(3.2)$ & $6(3.5)$ & $0(0)$ \\
PAC & $6(3.2)$ & $6(3.5)$ & $1(6.7)$ \\
PVC & $15(8.0)$ & $14(8.1)$ & $1(6.7)$ \\
Brugada-like electrocardiography & $6(3.2)$ & $6(3.5)$ & $0(0)$ \\
Right bundle branch block & $24(12.8)$ & $20(11.6)$ & $4(26.7)$ \\
Left bundle branch block & $4(2.1)$ & $3(1.7)$ & $1(6.7)$ \\
Deep Q wave in limb leads & $9(4.8)$ & $9(5.2)$ & $0(0)$ \\
Poor R wave progression & $23(12.3)$ & $21(12.2)$ & $2(13.3)$ \\
High voltage & $14(7.4)$ & $13(7.6)$ & $1(6.7)$ \\
ST elevation & $33(17.6)$ & $29(16.9)$ & $4(26.7)$ \\
ST depression & $6(3.2)$ & $5(2.9)$ & $1(6.7)$ \\
T wave abnormalities & $27(14.4)$ & $26(15.1)$ & $1(6.7)$ \\
IVCD & $5(2.7)$ & $5(2.9)$ & $0(0)$ \\
SSS & $6(3.2)$ & $6(3.5)$ & $0(0)$ \\
AF & $7(3.7)$ & $6(3.5)$ & $1(6.7)$ \\
Axis deviation* & $15(8.0)$ & $15(8.7)$ & $0(0)$ \\
WPW syndrome** & $5(2.7)$ & $5(2.9)$ & $0(0)$ \\
\hline *Eight pationts had right axis & & \\
\end{tabular}

*Eight patients had right axis deviation and 7 had left axis deviation.

**In 5 patients with WPW syndrome, 4 had type $A$ and 1 had type $B$.

SSS, sick sinus syndrome; AF, atrial fibrillation; AV, atrio-ventricular; PAC, premature atrial contraction; PVC, premature ventricular contraction; IVCD, intra-ventricular conduction disorder; WPW, Wolf-Parkinson-White.

In the present study the common reason for visiting hospital was consultation from other hospitals $(56.1 \%)$, and most of the patients were asymptomatic. Next, $38.5 \%$ of the patients visited for some mild complaints including palpitation and chest pain, although they were not regarded as specific symptoms. A recent study showed that heart failure was the most common presenting symptom at initial evaluation, and it differed to the present study in that only 8 patients presented with heart failure. ${ }^{5}$ Moreover, LVEF in the present study was relatively high at $60.2 \pm 7.6 \%$ as compared with $40.2 \pm 18.7 \%$ in the previous one. ${ }^{5}$ Therefore, adult INVM includes a wide spectrum of patients, from apparently healthy to severely diseased.

Although electrocardiographic changes in adult INVM have long been unknown, several studies recently reported a variety of abnormalities in ECG. ${ }^{2-6}$ The majority of the abnormalities have been considered non-specific, and this was also the case in the present study with Japanese patients. While the prevalence of normal ECG was relatively low, the characteristics of the abnormal findings were considered to be non-specific.

The great difference between the past studies and the present one might be the relatively high incidence of Brugadalike ECG. In the present study, Brugada-like ECGs were frequently observed in $3.2 \%$ of the patients. The incidence is higher than that in the general population in Japan $(0.01-$ $0.70 \%){ }^{13-15}$ One patient with Brugada-like ECG experienced VF and underwent ICD implantation. Although there were 6 INVM patients with Brugada-like ECG, the non-compacted areas were located only in the apex in all cases. Transmural voltage gradient across loose endocardium versus normally compacted epicardium, possible ischemia in the prominent trabeculations, or patchy fibrosis, ${ }^{16,17}$ and so on, might be attributed, at least in part, to cause Brugada-like ECG. There were not significant differences, however, in the UCG characteristics between the 6 patients and the others in the non-broad extension group, and the number of patients with this Brugada-like ECG was relatively small. Therefore, the mechanisms should be clarified in future larger prospective studies.

\section{Study Limitations}

The present study had several limitations. First, there was the retrospective nature of our analysis, which might lead to some inherent potential selection bias. Particularly, patients visiting for consultations from other hospitals would affect the frequency of ECG abnormalities. Second, the number of INVM patients was relatively small. Therefore, the frequency of rare ECG findings could be overestimated or underestimated. Finally, we could not investigate the rela- 

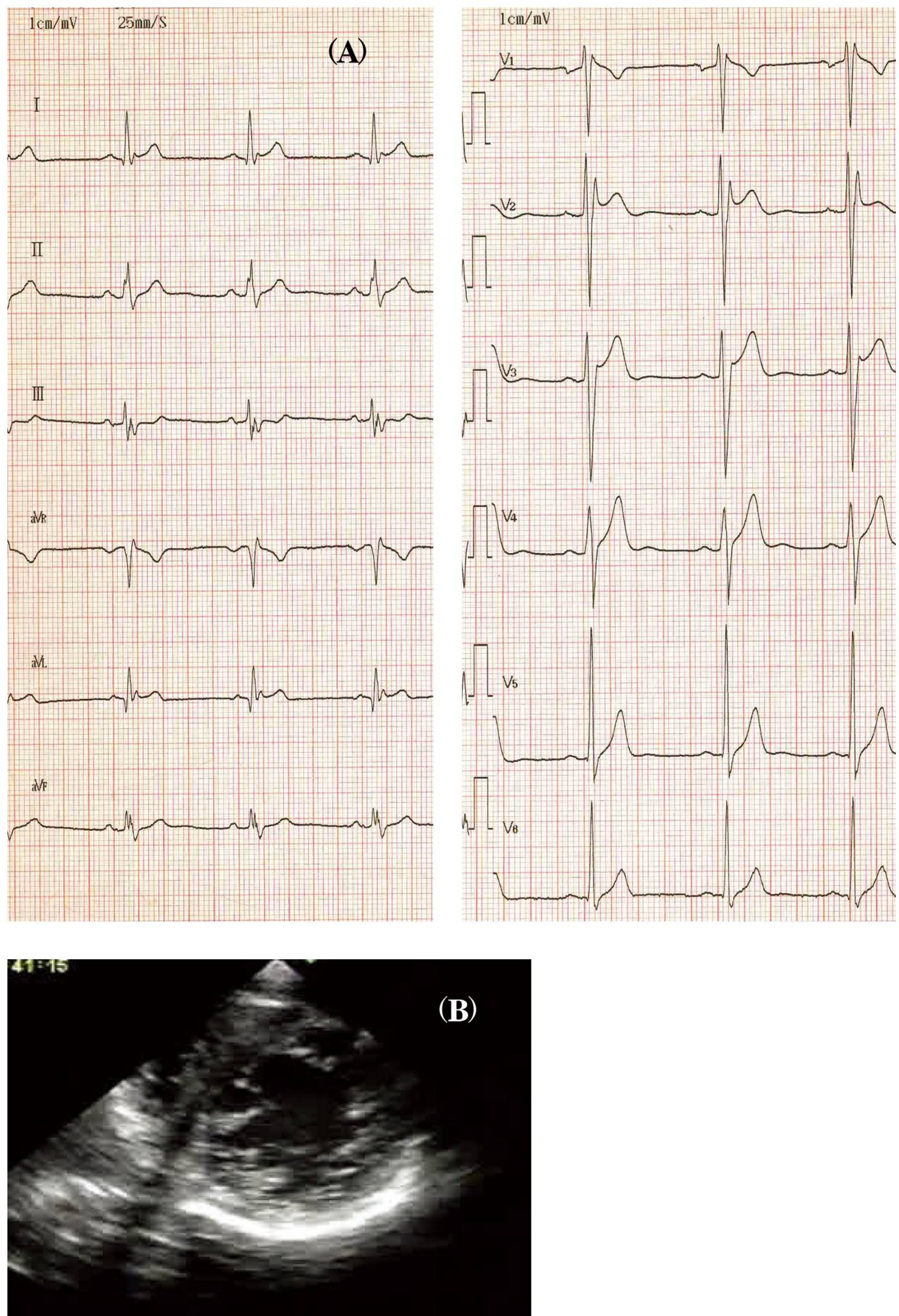

Figure. Twelve-lead electrocardiograms (ECG) and the echocardiogram (short axis view of LV apex) of a 22-year-old man with isolated non-compaction of ventricular myocardium, showing (A) Brugada-like ECG and (B) demonstrating LV non-compaction with thin epicardial and thickened endocardial layer with prominent deep recesses, respectively. 
tionship between the detailed area of non-compaction and ECG characteristics, because most of the patients had nonbroad extension.

\section{Conclusion}

Regardless of the limitations, the present study identified the prevalence and ECG findings of Japanese INVM patients in a hospital-based analysis.

\section{References}

1. Chin TK, Perloff JK, Williams RG, Jue K, Mohrmann R. Isolated noncompaction of left ventricular myocardium: A study of eight cases. Circulation 1990; 82: 507-513.

2. Oechslin EN, Attenhofer Jost CH, Rojas JR, Kaufmann PA, Jenni $\mathrm{R}$. Long-term follow-up of 34 adults with isolated left ventricular noncompaction: A distinct cardiomyopathy with poor prognosis. J Am Coll Cardiol 2000; 36: 493-500.

3. Lofiego C, Biagini E, Pasquale F, Ferlito M, Rocchi G, Perugini E, et al. Wide spectrum of presentation and variable outcomes of isolated left ventricular non-compaction. Heart 2007; 93: 65-71.

4. Aras D, Tufekcioglu O, Ergun K, Ozeke O, Yildiz A, Topaloglu S, et al. Clinical features of isolated ventricular noncompaction in adults long-term clinical course, echocardiographic properties, and predictors of left ventricular failure. J Card Fail 2006; 12: 726 733.

5. Steffel J, Kobza R, Oechslin E, Jenni R, Duru F. Electrocardiographic characteristics at initial diagnosis in patients with isolated left ventricular noncompaction. Am J Cardiol 2009; 104: 984-989.

6. Stanton C, Bruce C, Connolly H, Brady P, Syed I, Hodge D, et al Isolated left ventricular noncompaction syndrome. Am J Cardiol 2009; 104: 1135-1138.

7. Hook S, Ratiff NB, Rosenkranz E, Sterba R. Isolated noncompac- tion of the ventricular myocardium. Pediatr Cardiol 1996; 17: $43-$ 45.

8. Rohida A, Hajar HA. Ventricular conduction defect in isolated noncompaction of the ventricular myocardium. Pediatr Cardiol 1996; 17: 189-191.

9. Ichida F, Hanamichi Y, Miyawaki T, Ono Y, Kamiya T, Akagi T, et al. Clinical features of isolated noncompaction of the ventricular myocardium: Long-term clinical course, hemodynamic properties, and genetic background. J Am Coll Cardiol 1999; 34: 233-240.

10. Ritter M, Oechslin E, Sutch G, Attenhofer C, Schneider J, Jenni R. Isolated noncompaction of the myocardium in adults. Mayo Clin Proc 1997; 72: 26-31.

11. Ichida F. Left ventricular noncompaction. Circ J 2009; 73: 19-26.

12. Yasukawa K, Terai M, Honda A, Kohno Y. Isolated noncompaction of ventricular myocardium associated with fatal ventricular fibrillation. Pediatr Cardiol 2001; 22: 512-514.

13. Tohyo Y, Nakazawa K, Ozawa A. A survey in the incidence of right bundle branch block with ST segment elevation among normal population. Jpn J Electrocardiol 1994; 15: 223-226.

14. Miyasaka Y, Tsuji H, Yamada K, Tokunaga S, Saito D, Imuro Y, et al. Prevalence and mortality of the Brugada-type electrocardiogram in one city in Japan. J Am Coll Cardiol 2001; 38: 771-774.

15. Atarashi H, Ogawa S, Harumi K, Sugimoto T, Inoue H, Murayama $\mathrm{M}$, et al. Three-year follow-up of patients with right bundle branch block and ST segment elevation in the right precordial leads: Japanese Registry of Brugada Syndrome: Idiopathic Ventricular Fibrillation Investigators. J Am Coll Cardiol 2001; 37: 1916-1920.

16. Iwashima S, Ishikawa T, Ohzeki T. Delayed enhancement cardiac MRI in isolated noncompaction of the left ventricular myocardium in a child. Circ J 2008; 72: 676-678.

17. Kurita T, Matsuoka K, Hoshida K, Nakamori S, Ichikawa Y, Onishi $\mathrm{K}$, et al. Unique myocardial fibrosis pattern by late gadolinium enhanced magnetic resonance imaging in a patient with isolated noncompaction of the ventricular myocardium. Circ J 2010; 74: $381-382$. 